\title{
La neurociencia es un puente en el camino de construcción de la libertad
}

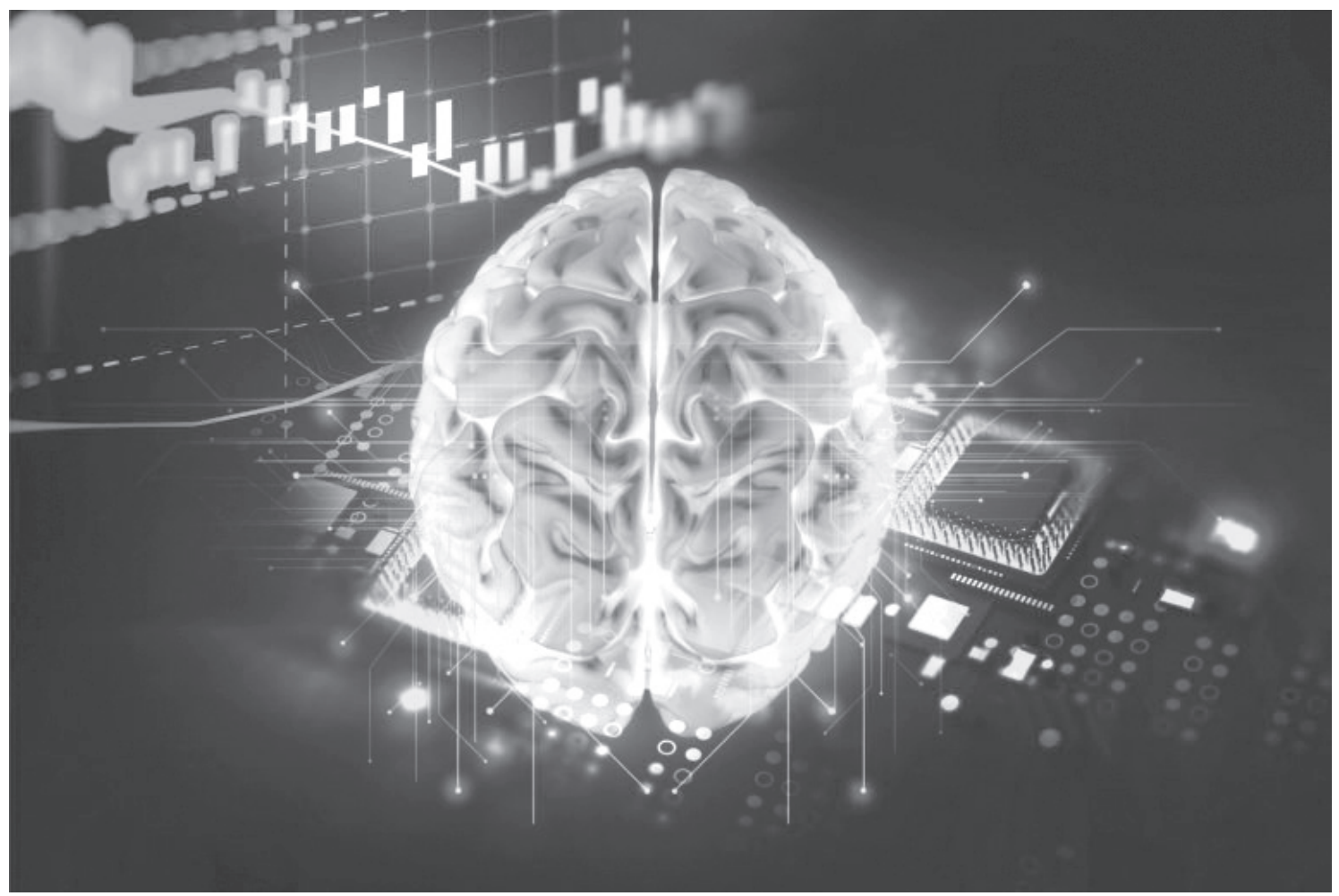

La libertad es una construcción cotidiana en diálogo entre los contextos biológicos y sociales. En uno y otro caso, la libertad no es una cosa en sí misma, es un concepto relacional. Solo hablamos de libertad en interacción, en presencia de otro. Hoy, gracias a la neurociencia, las preguntas de Platón sobre la justicia, un fundamento esencial para la discusión moderna sobre la libertad (desde el miedo de Hobbes, desde el Parlamento de Locke, desde la naturaleza de la ley Montesquieu, pero sobre todo desde la institucionalidad de Rousseau y de Mill, hasta las voces contemporáneas de Rawls, Habermas, Sen), crean vasos comunicantes entre las fronteras de las ciencias sociales y las naturales (no solo ya desde la lingüística emparentada con la biología, sino desde las disciplinas socioeconómicas con la neurociencia actual).
El debate que desde Comte ha acompañado a las ciencias sociales, el estatuto científico de estas disciplinas en relación con las ciencias de la naturaleza, parece haber alcanzado un nivel de complejidad en el nuevo horizonte de matemáticas probabilísticas, de altos niveles de computación matemática $y$, sobre todo, de la mirada inédita al interior de nuestro cerebro. ¡Llegamos primero a la Luna antes que desentrañar el diálogo complejo entre nuestras neuronas camino de entender el modo como el cerebro construye la cognición! Hemos alimentado nuestro cerebro por siglos, por horas en el aula, para poder estudiar la naturaleza del cerebro como órgano de nuestro cuerpo. La pregunta por el cerebro es una metapregunta: programamos nuestro sistema neuronal para indagar su propio funcionamiento. 
Y este camino al interior de nuestro sistema neuronal y centro de operaciones, el cerebro, apenas arroja los primeros resultados todavía borrosos, apenas descriptivos. Los mapas funcionales del cerebro son abstractos, de funciones gruesas entrecruzadas, de lógicas complejas (diversos componentes en interacciones de causalidad multivariada y multidireccional). Los refuerzos, los rechazos, la integridad de los procesos desde los insumos (inputs) sensoriales desde el entorno externo a los seres humanos a través de los sentidos; así como los insumos internos desde las estructuras siempre actuales de la corteza cerebral, construyen objetos (outputs) de representación de una realidad que converge entre el lenguaje que la lee y los incentivos que actualizan dicho lenguaje.

Estos acontecimientos de los últimos años desde la neurociencia deberían hacer parte del debate actual sobre los modelos pedagógicos, sobre la pedagogía, pero en especial sobre las didácticas. El alto nivel metalingüístico de casi todas las disciplinas hoy (entendido como el modo en que el entramado mismo del lenguaje con el que nombramos afecta lo nombrado), en particular las ciencias sociales, sumado a la coestructura biológica-lingüística siempre viva y actualizada en sus entornos, debe llevarnos a profundizar desde al menos los siguientes escenarios el tema educativo:

- Una atención muy especial a la infancia desde todas sus dimensiones: social, biológica, educativa, etc.

- Un debate riguroso desde la ciencia actual sobre los modelos educativos y sus didácticas, en general.

- De un modo particular, el estudio sobre manipulativos didácticos capaces de dar cuentas entre el modo como intuimos hoy el funcionamiento del cerebro y las actividades desarrolladas en el aula, en particular en los ámbitos de la construcción de procesos cognitivos y del modo como nutrimos la memoria.

- El modo de evaluación de la actividad docente, ya sea al evaluar a los educadores, ya sea sobre el modo como los educadores evalúan.

La neurociencia actual no solo debería arrojar luces sobre la tradición en el aula; el conjunto de la vida social y científica empieza a asumir igualmente este legado, aunque en unos escenarios con mayor o menor apropiación. La ciencia jurídica, la psicología, la política, la economía, la sociología en los centros de vanguardia del mundo ya dan cuenta de nuevas miradas epistemológicas sobre la construcción social y biológica de la realidad. Es hora entonces de reelaborar nuestro espíritu de la leyes que rigen el diálogo por la existencia entre el contexto de nuestro cuerpo iluminado por la sangre y el contexto social que engendra con su alimento el encuentro entre la célula y el signo, entre el animal y la cultura, entre el lenguaje y las lenguas. La sangre expuesta como consciencia nos define como seres humanos. No es suficiente la conciencia (moral) para construir la libertad, indagar los caminos complejos de la consciencia (neuronal) puede contribuir a educar seres más libres, más humanos; menos solitarios y más solidarios.

La neurociencia ha inundado todos los campos de la academia y de la vida moderna. En esta entrega de la Revista Papeles de la UAN nos ocupamos de modo especial de la neurociencia y sus vínculos con la enseñanza de diversos saberes. Otros temas, como el desempleo juvenil y la pedagogía aplicada tanto en el aula como en la resolución de conflictos, complementan nuestra entrega.

\section{Enrique Ferrer-Corredor}

